\title{
PURIFICAÇÃO DO ÓLEO DE FRITURA UTILIZANDO BIOMASSAS COMO ADSORVENTES PARA POSTERIOR PRODUÇÃO DE BIOCOMBUSTÍVEIS.
}

\author{
F. BRITO dos SANTOS $^{1}$, A. N FURLAN MENDES ${ }^{2}$ \\ ${ }^{1}$ Universidade Federal do Espírito Santo, Faculdade de Engenharia Química \\ 2 Universidade Federal do Espírito Santo, Departamento de Ciências Naturais \\ E-mail para contato: nanda_cat12@hotmail.com
}

\begin{abstract}
RESUMO - A preocupação com o meio ambiente e a necessidade de redução dos níveis de poluição são fatores que têm contribuído para a busca de combustíveis alternativos aos derivados de petróleo. Entre as alternativas encontradas, o biodiesel obtido a partir do óleo de fritura é uma alternativa técnica viável e comprovada por vários estudos. Com isso, a reciclagem do óleo de fritura vem ganhando espaço cada vez maior, pois além de ser uma opção de matéria-prima barata, o aproveitamento deste resíduo evita a degradação e diminui a poluição ambiental. No entanto, a principal dificuldade em utilizar o óleo de fritura para a produção do biodiesel é o alto índice de acidez que este apresenta devido à grande quantidade de ácidos graxos liberados durante as quebras das cadeias lipídicas do óleo quando este é submetido a elevadas temperaturas. Por essa razão, o óleo de fritura deve ser tratado antes de ser utilizado na produção de biodiesel. Este trabalho tem como objetivo tratar o óleo residual de fritura utilizando a casca de banana como material adsorvente para a redução da cor e do teor de acidez, visando a sua reutilização para a produção de biodiesel através da reação de transesterificação básica.
\end{abstract}

\section{INTRODUÇÃO}

A industrialização surgiu tempos atrás com o objetivo de crescer a economia mundial. Entretanto, este crescimento exacerbado está associado a uma demanda energética muita grande. A principal fonte de energia atualmente vem do petróleo; caracterizado como uma fonte de energia não renovável. Por conta deste fator nos dias atuais há uma preocupação em como substituir este hidrocarboneto por fontes renováveis. Uma das propostas mais prováveis na substituição dos derivados de petróleo são os biocombustíveis. Entre os biocombustíveis destaca-se o biodiesel, que é considerado uma mistura de monoésteres de ácidos graxos (ésteres graxos) que podem ser obtidos por esterificação de ácidos graxos ou por transesterificação de óleos e gorduras, compostos em grande parte de triglicerídeos (Meher et al, 2006).

A proposta do respectivo estudo consiste em utilizar óleo de fritura para síntese do biodiesel. Todavia, o mesmo necessita passar por um tratamento prévio, para redução do índice de acidez e aumento no grau de clarificação, isto ocorre por meio de um processo de adsorção que foi realizado por adsorção utilizando a casca de banana in natura como principal 
adsorvente, A fim de se obter um biodiesel que atenda aos parâmetros estabelecidos pela Agência Nacional de Petróleo (ANP), bem como avaliar a eficiência do tratamento do óleo de fritura obtido em estabelecimentos comercias, objetiva-se reduzir a coloração, índice de acidez e índice de peróxido do óleo residual de fritura e reduzir resíduos em processos químicos para minimizar o impacto ambiental.

\section{MATERIAIS E MÉTODOS UTILIZADOS}

As atividades experimentais foram desenvolvidas nos laboratórios de Pesquisa do Centro Universitário Norte do Espírito Santo (CEUNES/UFES). O óleo de fritura foi obtido por doação de estabelecimentos comerciais de São Mateus/ES. A casca de banana foi doada pelo restaurante universitário do CEUNES.

O óleo de fritura passou por um pré-tratamento que consistiu em filtração, para eliminar resíduos de alimentos, secagem com sulfato de sódio previamente seco em estufa por duas horas e resfriado em dessecador seguido de uma filtração a vácuo. Posteriormente, o óleo foi armazenado, sob refrigeração, em frasco âmbar.

As cascas de banana foram submetidas à secagem em estufa por aproximadamente $10 \mathrm{~h}$ a uma temperatura de $120^{\circ} \mathrm{C}$ sem nenhum tratamento prévio. Em seguida a casca de banana foi triturada em um liquidificador doméstico e peneirada em diversos meshs, a fim de obter granulometrias uniformes.

Inicialmente realizaram-se testes de adsorção utilizando-se $50 \mathrm{~g}$ de óleo bruto e as porcentagens mássicas de casca de banana em relação à quantidade de óleo de 1,0\%, 1,5\%, $2,0 \%$ e 3,0\%. Nestes testes o tempo reacional foi fixado em 60 minutos. Após a verificação de qual a melhor porcentagem mássica de adsorvente realizou-se testes variando-se o tempo reacional. Foram realizados testes nos tempos de 30, 90 e 120 minutos. A granulometria da casca de banana utilizada para a realização dos testes foi as partículas do fundo que passaram pela peneira com mesh 32. Utilizou-se o fundo, pois a quantidade de casca de banana disponível para se realizar todos os testes era maior. Todas as análises de adsorção foram realizadas em duplicata a temperatura ambiente e sob agitação magnética.

Para verificar quais parâmetros reacionais estudados até o momento é a condição ótima, a intensidade de degradação do óleo de fritura utilizado neste estudo foi analisada, antes e após o tratamento com o adsorvente, através da determinação do índice de acidez de acordo com a metodologia oficial da AOCS (Norma Ca 5a-40), e do índice de peróxido, de acordo com a metodologia oficial da AOCS (Norma Cd 8-53), como descrito por Tanamati e colaboradores (Brasil, 2000).

A fim de verificar a redução na coloração do óleo antes e depois do tratamento para posterior comparação, as medidas de absorbância foram realizadas em comprimentos de onda que correspondem ao máximo de absorbância, havendo variação de poucos nanômetros de $\lambda$ de uma amostra para outra (Skoog et al, 2002 e Vogel, 2002). Nos experimentos o valor do comprimento de onda que se manteve constante foi $535 \mathrm{~nm}$, e os cálculos realizados foram 
embasados na Norma Cd 3d-63 da AOCS (2004), que utiliza dados da absorbância do óleo bruto e do óleo tratado para cada amostra (Vargas, 2013).

\section{1 ÍNDICE DE ACIDEZ}

O teste de índice de acidez do óleo de fritura foi realizado de acordo com a metodologia oficial da AOCS (Norma Ca 5a-40), como descrito por Tanamati (2008).

Inicialmente foram pesados cerca de $2 \mathrm{~g}$ de óleo de fritura em balança analítica e adicionou-se então $25 \mathrm{~mL}$ da solução de éter etílico-álcool etílico $(2: 1 \mathrm{v} / \mathrm{v})$ e 2 gotas de indicador fenolftaleína. Em seguida, titulou-se com solução de hidróxido de sódio 0,01M.

O índice de acidez (IA) foi calculado através da relação entre a massa em miligramas de hidróxido de potássio consumidos por grama de amostra analisada, conforme mostrado na Equação (1).

$$
I A\left(\frac{m g K O H}{g}\right)=\frac{V \cdot C \cdot F_{C} \cdot 5,61}{m}
$$

Em que $\mathrm{V}$ é o volume de solução de $\mathrm{NaOH}$ gasto na titulação da amostra $(\mathrm{mL}), \mathrm{f}_{\mathrm{C}}$ é o fator de correção da solução de $\mathrm{NaOH}\left(\mathrm{f}_{\mathrm{C}}=\mathrm{C}_{\text {real }} / \mathrm{C}_{\text {suposta }}=0,985\right)$, C é a concentração da solução de $\mathrm{NaOH}(\mathrm{mol} / \mathrm{L})$ e m é a massa da amostra de óleo de fritura $(\mathrm{g})$.

\subsection{GRAU DE CLARIFICAÇÃO}

O teste do grau de clarificação óleo de fritura foi realizado de acordo com a metodologia oficial da AOCS (Norma Cd 3d-63), como descrito por Tanamati (2008).

Para obter o grau de clarificação tanto do óleo bruto como das amostra de óleo após o tratamento foi necessário medir a absorbância das substâncias citadas acima, de acordo com a equação (2).

$$
G C(\%)=\frac{A_{0}-A}{A_{0}} \times 100
$$

Em que Ao é a absorbância do óleo bruto (não clarificado) e A é a absorbância do óleo clarificado.

2.3 Índice de peróxido: O teste de índice de peróxido foi realizado de acordo com a metodologia oficial da AOCS (Norma Cd 8-53), como descrito por Tanamati (2008).

Inicialmente pesou-se em um erlenmeyer aproximadamente $5 \mathrm{~g}$ da amostra em balança analítica e adicionou-se $30 \mathrm{~mL}$ da solução ácido acético glacial-clorofórmio $(3: 2 \mathrm{v} / \mathrm{v})$ e 0,5 $\mathrm{mL}$ de solução de iodeto de potássio saturada, deixando-se reagir por 1 minuto em repouso e ao abrigo de luz. Em seguida, adicionou-se $30 \mathrm{~mL}$ de água destilada e titulou-se com solução de tiossulfato de sódio $0,1 \mathrm{~N}$. Posteriormente, adicionou-se $2 \mathrm{~mL}$ de solução indicadora de 
amido $1 \%$ e prosseguiu-se a titulação até desaparecimento da coloração azul da solução. $\mathrm{O}$ mesmo procedimento foi realizado com o branco. O resultado foi calculado com base na quantidade em miliequivalentes de peróxido por $1 \mathrm{Kg}$ de amostra, conforme mostrado na Equação (3).

$$
I P\left(\frac{m e q O_{2}}{K g}\right)=\frac{\left(V_{a}-V_{b}\right) \cdot C \cdot F_{C} \cdot 1000}{m}
$$

Em que $\mathrm{V}_{\mathrm{a}}$ é o volume de solução de tiossulfato de sódio gasto na titulação da amostra $(\mathrm{mL}), \mathrm{V}_{\mathrm{b}}$ é o volume de solução de tiossulfato de sódio gasto na titulação do branco $(\mathrm{mL}), \mathrm{C}$ é a concentração da solução de tiossulfato de sódio $\left(\mathrm{N}\right.$ ou eq/L), $\mathrm{f}_{\mathrm{C}}$ é o fator de correção da solução de tiossulfato de sódio $\left(\mathrm{f}_{\mathrm{C}}=\mathrm{C}_{\text {real }} / \mathrm{C}_{\text {suposta }}=0,962\right)$ e m é a massa de amostra $(\mathrm{g})$.

\section{RESULTADOS E DISCUSSÃO}

Após os primeiros testes de adsorção no qual foram modificadas as porcentagens mássicas da casca de banana em relação à massa de óleo não tratado, realizou-se análises no qual se mediu o índice de acidez, índice de peróxido e grau de clarificação de cada amostra, conforme descrito anteriormente. Para se avaliar a melhor relação mássica testada, observou-se a redução dos índices citados acima se comparando com o óleo "bruto". Os dados obtidos estão apresentados na Tabela 1.

Tabela 1 - Resultados das análises realizadas nas amostras de óleo de fritura obtidas antes e após os testes de adsorção, variando-se a relação mássica adsorvente/óleo de fritura.

\begin{tabular}{|c|c|c|c|}
\hline Amostra de óleo & $\begin{array}{c}\text { Índice de } \\
\text { acidez } \\
\text { (mg KOH/g) }\end{array}$ & $\begin{array}{c}\text { Índice de } \\
\text { peróxido } \\
\text { (meq } \\
\left.\mathrm{O}_{2} / \mathbf{K g}\right)\end{array}$ & $\begin{array}{c}\text { Grau de } \\
\text { clarificação } \\
(\%)\end{array}$ \\
\hline Óleo bruto & 6,8900 & 7,2448 & - \\
\hline $\begin{array}{c}\text { Óleo }(1,0 \% \text { de casca de } \\
\text { banana })\end{array}$ & 5,8165 & 5,5650 & 1,1 \\
\hline $\begin{array}{c}\text { Óleo }(1,5 \% \text { de casca de } \\
\text { banana })\end{array}$ & 5,6058 & 4,3350 & 1,1 \\
\hline $\begin{array}{c}\text { Óleo }(2,0 \% \text { de casca de } \\
\text { banana })\end{array}$ & 5,3460 & 5,6567 & 1,6 \\
\hline $\begin{array}{c}\text { Óleo }(3,0 \% \text { de casca de } \\
\text { banana })\end{array}$ & 5,1157 & 5,7502 & 1,1 \\
\hline
\end{tabular}

A porcentagem de $3 \%$ da casca de banana foi escolhida como melhor relação mássica, pois com esta porcentagem obteve-se a menor redução no índice de acidez dentre as relações mássicas testadas. Embora não tenha sido obtido o menor valor para o índice de peróxido e para o índice de clarificação, os mesmos parâmetros reduziram-se em relação ao óleo sem tratamento. 
Após a escolha da relação mássica, determinou-se o melhor tempo para que ocorressem as adsorções. Os dados obtidos estão apresentados na Tabela 2.

Tabela 2 - Resultados das análises realizadas nas amostras de óleo de fritura obtidas antes e após os testes de adsorção, variando-se o tempo de adsorção.

\begin{tabular}{cccc}
\hline $\begin{array}{c}\text { Tempo } \\
\text { (minutos) }\end{array}$ & $\begin{array}{c}\text { Índice de } \\
\text { acidez } \mathbf{( m g} \\
\mathbf{K O H} / \mathbf{g})\end{array}$ & $\begin{array}{c}\text { Índice de } \\
\text { peróxido } \\
\text { (meqO} \mathbf{~} / \mathbf{K g})\end{array}$ & $\begin{array}{c}\text { Grau de } \\
\text { clarificação (\%) }\end{array}$ \\
\hline Óleo bruto & 6,8900 & 7,2448 & - \\
30 & 5,1250 & 6,1329 & 6,0386 \\
60 & 5,1157 & 5,7502 & 1,0531 \\
90 & 3,8190 & 5,8359 & 3,4589 \\
120 & 4,1009 & 5,4108 & 4,6022 \\
\hline
\end{tabular}

Observa-se na tabela 2 há uma grande variação no grau de clarificação em relação aos tempos de 90 e 120 minutos, isto pode ter ocorrido devido a erros aleatórios e sistemáticos.

Enfatiza-se que em todas as análises efetuadas até o momento a granulometria não foi identificada. Sabe-se apenas que ao utilizar uma peneira de mesh 42 uma parte da casca de banana triturada passou pela mesma. A escolha do fundo se deu devido à maior quantidade de adsorvente obtida em relação às demais granulometrias retidas em outros mesh, e, portanto, maior quantidade de material para se realizar os testes descritos e outros que serão relatados no relatório final.

\section{CONCLUSÃO}

A adsorção utilizando biomassas adsorventes é um processo de baixo custo operacional que proporciona resultados favoráveis. Com isto, o uso da casca da banana como biomassa adsorvente é favorável para a diminuição do acúmulo desse resíduo agroindustrial e ainda estará contribuindo para purificação de materiais contaminados.

O respectivo trabalho mostrou que as cascas de banana podem ser processadas e convertidas para serem utilizadas como adsorventes, pois possuem grandes superfícies de contato se particuladas, alta capacidade de expansão, excelentes características mecânicas sendo convenientes para uso em larga escala além de apresentarem grande potencial para adsorver contaminantes nocivos, diminuir consideravelmente a acidez do óleo de fritura bem como o índice de peróxido concomitante ao aumento do grau de clarificação da substância em estudo.

\section{REFERENCIAS}


Estudo comparativo de sistemas de epoxidação do óleo de soja, Brasil, M. C.; dissertação de mestrado.

SKOOG, HOLLER, NIEMAN, Princípios de Análise Instrumental, $5^{\text {a }}$ Edição, Editora Bookman, São Paulo-SP, 2002.

SKOOG, WEST, HOLLER, CROUCH, Fundamentos de Química Analítica, Tradução da $8^{\mathrm{a}}$ Edição norte-americana, Editora Thomson, São Paulo-SP, 2006.

TANAMATI, A. A. C. Instabilidade oxidativa do óleo de soja submetido à fritura de alimentos congelados. 2008. 102 f. Tese (Doutorado em Ciências) - Programa de PósGraduação em Química, Universidade Estadual de Maringá, Maringá, 2008. [1] MEHER, L. C.;/ SAGAR, D. V.; NAIK, S. N.; Technical aspects of biodiesel production by transesterification - a review. Renewable and Sustainable Energy Review, n. 10, p. 248-268, 2006.

TOSE, L. V.; SOARES, A. B. Estudo comparativo da clarificação do óleo residual de fritura pelo emprego do bagaço de cana-de-açúcar e das cascas de arroz in natura. In: Encontro capixaba de Química, 3., 2011, Vitória, Anais... Vitória: ENCAQUI, 2011. 1 CD-ROM.

Tratamento do óleo de fritura utilizando fibra de coco para posterior aplicação na produção de biocombustíveis, Vargas, T. V.; Trabalho de conclusão de curso.

VOGEL, Análise Química Quantitativa, 6º edição, LTC editora, Rio de Janeiro- RJ, 2002. 